\title{
Gebelikte Madde Kötüye Kullanımı ve Hemşirelerin Sorumlulukları
}

\author{
Substance Abuse in Pregnancy and Responsibilities of Nurses
}

Aydan AKKURT YALÇINTÜRK

ÖZ

Madde terimi, alkol, tütün, yasal ilaçlar ve yiyeceklerle yasal olmayan ürünleri içeren geniş bir bakış açısını yansıtır. Tüm dünyada olduğu gibi ülkemizde de madde kötüye kullanımı giderek büyüyen bir toplum sağlı̆̆ sorunudur. Madde kötüye kullanımı bağımlılık, kontrolsüz cinsel ilişki, fuhuş, cinsel yolla bulaşan hastalıklar riskini de beraberinde getirmektedir. Erkek cinsiyette daha sık gibi düşünülse de kadınlardaki madde kötüye kullanım oranı da gün geçtikçe erkeklerinkine yaklaşmaktadır.

Yenidoğan yoksunluk sendromu; gebelik süresince fiziksel bağımlılık yapan madde kötüye kullanımı olan annelerin bebeklerinde doğum sonrası karşılaştıkları maddenin eksikliğine bağlı bulguların görüldüğü klinik bir tablodur. Özellikle gebelik boyunca madde kötüye kullanımı sonucunda anne, yenidoğan ve çocuk üzerinde bir takım zararlı etkiler oluşmaktadır. Bu etkiler dikkate alınarak, hemşirelerin konuya ilişkin bilgilerinin arttırılması ve sorumluluk üstlenmelerinin sağlanması gerekmektedir.

$\mathrm{Bu}$ derleme son zamanlarda ülkemizde artan gebelik süresince madde kullanan annelerin bebeklerinde görülen yenidoğan yoksunluk sendromu konusunu ve bu konuda hemşirelere düşen sorumlulukları vurgulamak için hazırlanmıştır.

Anahtar Kelimeler: Yenidoğan yoksunluk sendromu, madde kötüye kullanımı, hemşire

\begin{abstract}
Substance term reflect a perspective that includes alcohol, tobacco, legal drugs and food, illegal products. As in the whole world, substance use in our country is a growing problem of community health. Substance use also brings with it the risk of addiction, uncontrolled sexual intercourse, prostitution, sexually transmitted diseases. Although male gender is thought to be more common, the rate of substance use in females is approaching to men day by day.

Neonatal abstinence syndrome is a clinical chart showing the findigs of the material absence of the substance that they meet after birth in the infants of the mother who are using physically addictive substance during the pregnancy. Especially, as a result of substance use during pregnancy by mother, there are some harmful effects on neonatal and child. Taking these effects into consideration, it is necessary to increase the knowledge of nurses about subject and take responsibility.

This article has been prepared about increasing neonatal abstinence syndrome seen in the infants of mothers who use drugs is during the pregnancy in our country recently and the responsibilities of the nurses in this regard.

Keywords: Neonatal abstinence syndrome, substance abuse use, nurse
\end{abstract}

\section{GíRiş}

Madde terimi, alkol, tütün, yasal ilaçlar ve yiyeceklerle yasal olmayan ürünleri içeren geniş bir bakış açısını yansıtır. Madde kötüye kullanımı tüm dünyada giderek artan sorunlardan biridir. Diğer ülkelerde olduğu gibi ülkemizde de madde kötüye kullanımı son yıllarda giderek büyüyen, önemli bir halk sağlığ 1 sorunudur. Ülkemizde bağımlılık yapan ilaçların özel reçete ile satılması nispeten kontrollü kullanımlarını sağlarken, sigara, alkol ve yasadışı maddelerin kullanımında bu kontrol ortadan kalkmaktadır (1).
Aydan AKKURT YALÇINTÜRK (四)

İstanbul Arel Üniversitesi Sağlık Bilimleri Yüksekokulu Hemșirelik Bölümü Türkoba Mahallesi Erguvan Sokak No:26 Tepekent-Büyükçekmecel ISTANBUL

e-posta: aydanyalcinturk@arel.edu.tr 
Madde kötüye kullanımı daha çok erkek cinsiyetin problemi gibi düşünülse de yapılan son çalışmalarda kadın erkek arasındaki madde kötüye kullanım sıklığı ile ilgili farkın giderek daraldığı görülmektedir. Bunun yanı sıra; madde kötüye kullanımının kadınların üzerinde erkeklere kıyasla daha farklı ve yıkıcı etkiler yaptığı gösterilmiştir. Kadınların annelik ve doğurganlık özelliklerini dikkate aldığımızda, maddenin toplumsal yıkıcı etkisini gözardı etmemek gerekir $(2,3,4)$.

Kadının madde kötüye kullanımına neden olan risk faktörleri (5);

- Kadınlar fiziksel açıdan kullanılan maddelerden daha kolay etkilendiğinden dolayı bağımlılığa daha yatkındırlar.

- Liseden üniversiteye geçiş, evlenme gibi gelişimsel dönemler, kadınların madde kullanımı açısından risk taşıdığı zamanlardır.

- Kadınlar sorunlar ile başa çıkmak, baskıları azaltmak veya kilo kaybetmek gibi nedenlerle madde kullanmaya eğilimlidirler.

- Cinsel olarak kötüye kullanım yaşayan kadınlar madde kötüye kullanımına daha yatkındır. Onların madde kötüye kullanımı daha erken başlamakta ve daha fazla madde kullanmaktadırlar.

- Kadının travmatik yaşantısı ile madde kötüye kullanımı arasında güçlü bir ilişki vardır.

Kadınlarda madde kötüye kullanımı üzerine yapılan araştırmaların hemen hepsinde istismara uğrama en önemli risk faktörlerinden biridir (6).

Gelişmiş ülkelerde hamile kadınların \%4,4’ü yasadış1 ilaç kullanmaktadır. Ülkemizde ise gebe kadınlarda bu alanda yapılmış yeterli çalışma bulunmamaktadır (7). Oysaki gebelik boyunca madde kötüye kullanımı sonucunda anne, yenidoğan ve çocuk üzerinde bir takım zararlı etkiler oluşmaktadır. Yapılan araştırmalarda bir ya da birden fazla maddeye anne karnında maruz kalan çocuklarda sonraki dönemde ortaya çıkacak tıbbi sorunlar \%75 oranında bulunurken, maruz kalmayan çocuklarda \%27 bulunmuştur (8). Örneğin; eroin kullanan annelerin bebeklerinde yenidoğan yoksunluk sendromunun görülme sıklığg $\% 16-90$ arasında değişmektedir. Madde kötüye kullanımı büyüme, öğrenme, motor gelişim bozukluklarına, dil, dikkat, hafiza gibi bilişsel bozukluklara, dikkat eksikliği ve hiperaktivite bozukluğu gibi çocukluk çağı gelişim sorunlarına da neden olabilmektedir. Ayrıca bu çocuklarda depresyon ve anksiyete riskinin arttığı düşünülmektedir $(9,3,10)$.

\section{Yenidoğan Yoksunluk Sendromu}

Yenidoğan yoksunluk sendromu; gebelik süresince fiziksel bağımlılık yapan madde kötüye kullanımı olan annelerin bebeklerinde doğum sonrası karşılaştıkları maddenin eksikliğine bağlı bulguların görüldüğü klinik bir tablodur (11).

Bulgular kullanılan maddeye ve kullanma süresine göre değişir. Yenidoğanda en sık merkezi sinir sistemi, gastrointestinal sistem ve solunum sistemi etkilenmektedir. Konvülziyon (nöbet), tremor (titreme) ve hiperirritabilite en belirgin bulgulardır. Bebek çok öfkeli görünür, çoğu zaman oldukça hareketli ve sıkıntılıdır. Uzun süre uyuyamaz, yüksek ve tiz bir sesle ağlar. Konvülziyonlarda istem dışı göz hareketleri, bakışın sabitleşmesi ve kol-bacaklarda titreme olmaz. Kol ve bacaklarda genellikle kaba hareketler göze çarpar. Kolların hareketi kanat çırpmayı andırır. Bebeğin emme içgüdüsü çok fazladır. Ancak bebeğin her öğünden sonra kusması, beslenme probleminin habercisidir. Yenidoğanların \%30-50'sinde ishal ve buna bağlı olarak su kaybı ve kan elektrolit düzensizlikleri görülür. Ek olarak yenidoğan yoksunluk sendromu olan bebeklerin \%30’unda anormal EEG bulguları gözlenmiştir $(9,7)$.

Klinik bulgular genelde 48-72 saat içinde ortaya çıkmaktadır. Anne emzirme döneminde bağımlılık yapan maddeleri kullanmaya devam ederse bulguların ortaya çıkması gecikmektedir. Özellikle anne sütü ile beslenen yenidoğanlarda bulguların ortaya çıkması birkaç gün gecikebilir. Buna karşın doğumdan önce son 24 saat içinde bağımlılık yapan maddeyi kullanmışsa bulgular daha erken çıkabilmektedir. En son madde alımının üzerinden bir haftadan fazla zaman geçtiyse yoksunluk görülme ihtimali daha düşüktür $(12,13,14)$.

Yenidoğanda maddenin tespiti için idrar, kan, mekonyum (bebeğin ilk kakası) incelemesi ve saç analizi gibi çeşitli testler kullanılabilir. En iyi tanı metodu ise bebeğin ilk mekonyumunda bağımlılık yapan maddenin saptanmasıdır. Ancak mekonyumun anne sütü veya mama ile beslenme öncesialınması gerekir. Yenidoğan bebeklerde idrar analiziile yetinilmeyip mekonyum incelemesinin de yapilması gerektiği belirtilmekte olup, idrarda negatif bulgu veren vakaların mekonyumlarında madde metebolitlerinin tespit edildiğini gösteren araştırma bulguları vardır. Yenidoğan bebekte saç miktarının az olması ve bazı kültürel 
farklılıklardan dolayı saç örneğinin alınamaması saç analizi yönteminin dezavantajıdır. Annenin öyküde bağımlılık yapan maddeyi kullandığını belirtmesi tanının konulmasını kolaylaştırmaktadır. Ülkemiz gibi çevresel etkileşimin fazla olduğu toplumlarda ise anneler genelde bağımlılık yapıcı ilaç kullandığını saklamaktadır. Genelde çevresel ya da sosyal nedenler ile bu bilgi gizlendiğinden tanı konulması gecikmektedir $(7,15,1)$.

Yenidoğanda oluşan yoksunluk bulguları \%30-80 oranında tedavi gerektirirken; tedaviye yoksunluk bulguları tamamen kaybolana kadar devam edilmektedir. Madde bağımlısı annelerin bebeklerinde tedavinin ana prensipleri; bebeğin büyüme ve gelişiminin sağlanması, doğum sonrası anne bebek ilişkisinin kurulması, bebeğin konforunun sağlanması ve konvülziyon tedavisini içermektedir. Tedavide opiatlar, benzodiazepinler ve fenobarbital kullanılır. Sözü edilen ilaçlar, genellikle birkaç günde dozu azaltılarak kesilirken bazı vakalarda bu ilaçların haftalarca uygulanması gerekebilir. Bu ilaçlarla birlikte yenidoğanın 1şıksız, sakin ve sessiz bir ortama alınması, uyaranların minimuma indirilmesi, yalancı emzik verilmesi ve gevşek kundak uygulanması sakinleşmesi için önemlidir. Anneden geçen madde oranının yoğun olduğu ve erken dönemde etkili tedaviye başlanmadığı durumlarda, yenidoğan konvülsiyon ve ölümleri görülebilir $(9,1)$.

İntrauterin eroin maruziyeti olan bebeklerde mortalite tek başına yoksunluk semptomları nedeniyle değil aynı zamanda prematürite, enfeksiyon ve perinatal asfiksi gibi komplikasyonları nedeniyle olmaktadır. (7).

\section{Madde Kötüye Kullanımının Engellenmesinde Servis Hemşirelerinin Sorumlulukları}

Madde kötüye kullanımının engellenmesinde ve bırakılmasında hemşire kilit role sahiptir. Ülkemiz gibi gelişmekte olan ülkelerde madde bağımlılığı olan gebe ile karşılaşma sıklığı giderek artmaktadır. Bu nedenle hemşirelerin başta madde kötüye kullanımını engelleyici girişimlerde bulunmaları, madde bağımlılı̆̆ şüpheci davranmaları böylece madde kullanan gebe kadınları erken dönemde belirlemeleri gerekmektedir. Bunun için ev ziyaretleri ile madde kötüye kullanımı yönünden riskli aileler tespit edilerek destekleyici müdahaleler uygulanabilir.

Madde kötüye kullanımı olan kadınların özelliklerinin bilinmesi, risk gruplarının erken tespiti ve müdahaleye başlanması yönünden önemlidir. Bu özellikler (1);
- Kendi ebeveynleri ile olumlu ilişki deneyimi olmayan kadınlar,

- Olumlu ebeveyn rol modeli görmemiş olanlar,

- Aile içi şiddetin uygulandığı bir ortamda yaşamış olanlar,

- Aile ortamında fiziksel, duygusal, cinsel istismar eve ihmale uğramış olanlar,

- Ebeveynleri madde bağımlısı olanlar,

- Evliliklerinde, eşleri tarafindan istismar edilenlerdir.

Yukarıdaki özellikleri taşıyan bireyler toplum taramaları ile tespit edilebileceği gibi, hemşirelerin hizmet vermek üzere karşılaştıkları bireylere yönelik kapsamlı sağlık değerlendirmesi ile de belirlenebilir (1).

Hemşirelerin madde kullanan kadınlara tedaviye başlamadan önce öncelikle; maddenin kendisi ve çocuğunun sağlığına yönelik oluşturduğu risklerden ve madde kötüye kullanımının bırakılması sonrası sağlıklarında meydana gelecek düzelmelerden söz etmeleri kadınların maddeyi bırakma konusundaki motivasyonlarını artıracak ve tedaviye bağlanmalarını sağlayacaktır (16).

Tüm bunların yanında sağlı personelinin klinik bulguları olan bebeklere erken ve uygun tedaviyi sağlamaları, yenidoğan yoksunluk sendromu ile ilişkili sorunları azaltacaktır (14).

Annenin madde bağımlılı̆̆ı açısından taranması genellikle karmaşık bir durumdur. Görüşmeci hemşire anne ile iyi bir ilişki kurmalı; yargılayıcı olmadan, ucu açık sorularla tüm hikâyeyi elde etmelidir (14).

Hemşire gebelikte madde kötüye kullanımı ile ilgili bildirim zorunluluğu ve konunun hukuki konuları konusunda bilgi sahibi olmalıdır. Madde kullanan annelerin HIV pozitif olma riskleri yüksektir. Bu olgularda sifiliz, gonore, klamidya, hepatit B ve C, HIV ve tüberküloz hastalıkları taranmalıdır. HIV antikoru pozitif bulgu verenlerin bebeğini emzirmemesi gerekir. Yine narkotik, kokain, amfetamin ve marihuananın sütle geçmesi nedeniyle, bu maddeleri kullanan annelerin bebeklerini emzirmesi kontrendikedir (1).

Madde bağımlısı anneler, çocuğuna nasıl davranacağı ve onunla nasıl ilişkiye geçeceğini çoğu zaman bilemeyebilir. Özellikle bebek istenmeyen gebelik sonucu olmuşsa, anne adölesan ise, anne gebelikte tedavi programına alınamamış ve doğum sonrası yoğun yoksunluk tablosu yaşıyorsa, anne-bebek bağlilığ 1 problemi riski daha da artar. Anne bu konular ile ilgili mutlaka erken dönemde bilgilendirilmeli ve 
desteklenmelidir. Anne ve çocuktaki yoksunluk tablosunun kontrol altına alınması gerekir. Annelerin kaygı, suçluluk gibi duygularını ortaya koyması için firsat tanınmalı, bu duyguların kabul edildiği mesajı verilmelidir. Annelerin tüm olumlu yönleri vurgulanmalı, küçük başarıları övgü dolu sözlerle desteklenmeli, çocuğun negatif tepkilerinin anneyi reddetme anlamına gelmediği açıklanmalıdır $(17,1)$.

Madde bağımlısı bireylerin kendilerine güvenlerinin az, başkalarına güvenmelerinin güç olduğu dikkate alınarak, hümanistik bir yaklaşımla terapötik iletişim yöntemlerinin kullanılması, mümkünse aynı personelden hizmet almalarının sağlanması faydalı olur (18).

Bunlara ek olarak madde bağımlısı anne çocukları istismar ve ihmale uğrama ihtimalleri yüksektir bu nedenle ciddi sosyal destek ve takibe ihtiyaçları vardır (14).

Hemşirelerin yenidoğan yoksunluk sendromu ile karşılaştı̆̆ında yapması gerekenler $(19,20)$;

- Gebelikte madde bağımlılı̆g belirlenebilmeli ve değerlendirilebilmelidir.

- Gebenin/ Annenin kullandığı madde miktarı ve kullanım özellikleri öğrenilmelidir.

- Annenin madde kullanmasına bağlı olarak ortaya çıkan hastalıkları yenidoğanda tespit edebilmelidir.

- Tehlikeli madde kötüye kullanımı, bağımlılık ve madde kötüye kullanan kişilerin davranışları konularında yakınları bilgilendirilmelidir.

- Gebe/anne ile madde etkisinde olmadığı zaman konuşmaları gerektiği konusunda aile üyeleri uyarılmalıdır.

- Eğer gebe/anne tedaviye gelmek istemiyorsa, tedavi için başvuracağını değil, danışmanlık almak için başvuracağının söylenmesi rahatlatıcı olur.

- Sorumluluğunu onun yerine yakınlarının alması sık yapılan bir hatadır. $\mathrm{Bu}$ nedenle yakınları bu konuda uyarılmalıdir.

- Tedavi sürecinde yoksunluk belirtileri açısından hastayı gözlemler, bilinç takibi yapar, sık yaşam bulgularını, yönelimini değerlendirir, tremor, terleme, halusinasyon, ajitasyon, hezeyan, konvulsüyon varlığını takip eder, yoksunluk belirtilerinin şiddetini değerlendirir, kaydeder.

- Fiziksel yoksunluk belirtilerini gidermek amaciyla gerekli girişimleri planlar ve uygular, destekleyici bakım sağlar, yoksunluk belirtilerine ilişkin tedavi ekibini bilgilendirir.

- Hastaların öz bakımını yapması için teşvik eder, destekler, gerektiğinde yapar.

- Annenin bebeğinin bakımını yapması için teşvik eder, destekler.

- Hastanedeki tedavi ekibi ile işbirliği içinde hasta/hasta ailesine yönelik eğitim ihtiyacını saptar, psikolojik eğitimi planlar, hastanın aktif katılımını teşvik eder, eğitimi uygular ve değerlendirir.

- Hastaların ve ailelerin gereksinimlerine yönelik eğitim broşürleri/kitapçıklar hazırlar, ihtiyaç halinde revize eder.

\section{Sonuç ve Öneriler}

Gebelikte madde kötüye kullanımı hem anneyi hem bebeği hem de toplumu zor durumda birakan ciddi bir toplum sorunudur. Madde kötüye kullanımının giderek artması ve gebelikte madde kötüye kullanımının yenidoğana ciddi etkisi dikkate alınarak, hemşirelerin konuya ilişkin sorumluluk üstlenmeleri toplum sağlığının geliştirilmesi açısından önemlidir. Maddenin kötüye kullanımının önlenmesi konusunda önemli role sahip olan toplum sağlığı hemşiresinin bu konuda mutlaka hizmet içi eğitim alması gerekir.

Madde kullanan gebelerin tespit edilmesi, tedavi ve takibe alınması, ayrıca madde kullanan kadın hasta ve eşlerinin gebelik ve oluşabilecek sağlık sorunları açısından bilgilendirilmesi oldukça önemlidir.

\section{KAYNAKLAR}

1. Cimete G. Gebelikte madde kullanımının anne, fetüs ve yenidoğan üzerine etkisi. Atatürk Üniv. Hemşirelik Yüksekokulu Dergisi 2002;5(1): 68-77

2. Arslan HN, Terzi Ö, Dabak Ş, Pekşen Y. Substance, cigarette and alcohol use among high school students in the provincialcenter of Samsun, Turkey. Erciyes Med J 2012; 34: 79-84.

3. İzci F, Bilici R. Gebelerde Madde Kullanımı: Görülme S1klığg ve Etkileri - Substance Use Among Pregnant Women: Frequency and Effects. Bağımlılık Dergisi 2015;16(1):26-34.

4. Tuchman E. Women and addiction: the importance of gender issues in substance abuse research. J Addict Dis 2010; 29(2):127-38.

5. Kutlu Y. Substance Use and Abuse Among Women. Psikiyatri Hemşireliği Dergisi - Journal of Psychiatric Nursing 2011;2(2):90-93. 
6. Yücel H. Kadınlarda alkol ve madde kullanımı. PDF Dökümanı (Erişim Tarihi: 17.11.2017).

7. Özdemiroğlu N, Kara S, Kurt CC, Arıkan Fİ, Dallar Bilge Y. Neonatal yoksunluk sendromu olan prematüre bebek Premature infant with neonatal abstinence syndrome. Ege T1p Dergisi / Ege Journal of Medicine 2014;53(2): 102-105.

8. Smith L, Sarrory J, Coures J, Burns E. Alcohol Consumption During Pregnancy: Cross-Sectional Survey. Midwifery 2014; 30(12):1173-8.

9. Can E, Bülbül A, Uslu S, Güran Ö, Nuhoğlu A. Neonatal yoksunluk sendromu. Şişli Etfal Hastanesi Tip Bülteni 2010;44(3):124-127.

10. Aktaş S, Karakurt TL, Saygı M. Unexpected Cause of Neonatal Seizure: In Utero Heroin Exposure. Gazi Medical Journal 2016;27(3): 158-159.

11. McKnight S, Coo H, Davies G, et al. Rooming-in for infants risk of neonatal abstinence syndrome. Am J Perinatol 2016; 495-501.

12. Stover MW, Davis JM. Opioids in pregnancy and neonatal abstinence syndrome. Semin Perinatol 2015; 39: 561-565.

13. Sinha C, Ohadike P, Carrick P, Pairaudeau P, Armstrong D, Lindow SW. Neonatal outcome following maternal opiate use in late pregnancy. Int J Obstet Gynaecol 2001; 74:241-246.
14. Oğuz MM, Acar M, Polat E, Akçaboy M, Tuygun N, Açoğlu Altınel E, Şenel S, Dağlı Şahin F. Madde bağımlısı adolesan anne ve bebeği. Çocuk Sağlığ1 ve Hastalıkları Dergisi 2016; 59: 68-71

15. Bozkaya D, Öktem A, Yurdakök M. Eroin kullanan anne ve neonatal yoksunluk sendromu. Çocuk Sağlığı ve Hastalıkları Dergisi 2016; 59: 72-75

16. Sieck CJ, Heirich M, Major C. Alcohol counseling as part of general wellness counseling. Public Health Nurs 2004; 21(2):137-143.

17. Velez M, Jansson LM. The Opioid dependent mother and newborn dyad: non-pharmacologic care. J Addict Med 2008; 2: 113-120.

18. Mathre ML. Substance abuse in the community, Community Health Nursing, M Stanhope and 1 Lancaster (Ed.), Fourth Edition, StLouis, Baltimore, Chicago, NewY ork, Philadelphia, London, Madrid, MexicoCity, Sydney, Tokyo, Toronto: 1996; 709-29.

19. Kaya Y, Şahin N. Kadınlarda Madde Kullanımı ve Hemşirenin Rolü. Hemşirelikte Eğitim ve Araştırma Dergisi 2013;10 (1): 3-7

20. Potter B, Fleming M F. Obstetrics and gynecology resident education in tobacco, alcohol, and drug use disorders. Obstet Gynecol Clin N Am 2003; 30(3):583-599. 
